\title{
A Neuropathic Deficit, Decreased Sweating, Is Prevented and Ameliorated by Euglycemia in Streptozocin Diabetes in Rats
}

Claudio Cardone and Peter James Dyck

Peripheral Neuropathy Research Laboratory, Mayo Clinic and Mayo Foundation, Rochester, Minnesota 55905

\begin{abstract}
Decreased sweating, especially of feet and legs, occurs in human diabetic neuropathy. It might be studied in experimental diabetes to characterize it, elucidate its mechanisms, and determine whether it can be prevented or treated. The pilocarpine-induced sweat responses (SR) in the hind foot pads of groups of control and streptozocin diabetic rats, in good (GC) and in poor (PC) glycemic control and with a crossover design after 20 wk of diabetes, were evaluated with the silicone mold sweat test to determine the number of sweat droplets per group of foot pads. The SR was dose dependent and reproducible. The SR disappeared with denervation and reappeared with reinnervation; denervation hypersensitivity did not develop. In the GC group, euglycemia was achieved by regulating the caloric intake and using multiple daily injections of Ultralente insulin. The SR was not different from that of the control group for up to $136 \mathrm{~d}$. In the PC group, the SR became abnormal ( $P$ $<0.005)$ at $16 \mathrm{~d}$ and progressively worsened: $40 \%$ of baseline values at 14 wk $(P<0.001)$. After restoring euglycemia in the PC group, a normal SR occurred at $12 \mathrm{~d}$. These results show that one human neuropathic deficit, failure of sweating, can be prevented or ameliorated by good glycemic control. (J. Clin. Invest. 1990. 86:248-253.) Key words: hyperglycemia • silicon mode sweat test • diabetic neuropathy $\bullet$ sweating
\end{abstract}

\section{Introduction}

The complications of retinopathy, nephropathy, neuropathy, and atherosclerotic occlusive disease of heart, brain, and limbs are major causes of morbidity and death in diabetes mellitus. Abnormality of nerve conduction occurs in $\sim 75 \%$ of diabetics, and symptomatic degrees of neuropathy in $\sim 10 \%$ (1). Despite the frequency and the severity of these complications, there is insufficient information on their natural history, cause, and treatment. Evidence from prospective trials that normalization of glycemia can prevent or ameliorate diabetic neuropathy is not conclusive (2-6).

Experimental models of diabetes have certain advantages

Presented in part at the 41 st Annual Meeting of the American Academy of Neurology, Chicago, IL, 13-19 April 1989.

Dr. Cardone is a visiting scientist from the Department of Internal Medicine, Padua University, Italy.

Address reprint requests to Dr. Cardone, Instituto di Medicina Interna, Universita di Padova, via Giustiniani 2, 35128 Padova, Italy; or to Dr. Dyck, Peripheral Neuropathy Research Laboratory, Mayo Clinic, 200 First Street SW, Rochester, MN 55905.

Received for publication 20 October 1989 and in revised form 21 February 1990.

J. Clin. Invest.

(c) The American Society for Clinical Investigation, Inc.

0021-9738/90/07/0248/06 \$2.00

Volume 86, July 1990, 248-253 over the human disease in the study of diabetic complications. Genetic variability, and variability related to duration and amount of hyperglycemia, diet, treatment, and other variables can be minimized. Tissue can be taken at desired times. Already, study of experimental models of diabetic neuropathy has produced insights into functional, biochemical, axonal flow, and structural alterations and putative mechanisms (7-10). Euglycemia prevents some of the functional and biochemical alterations (7-14), but it has not been shown to prevent or ameliorate neuropathic deficits encountered in human diabetic neuropathy.

In this study, the pilocarpine-induced silicone mold sweat response $(\mathrm{SR})^{1}(15,16)$ in control and in diabetic rats, in good (GC) and in poor glycemic control (PC), was quantitated in a crossover design. The end point was the number of sweat droplets per group of foot pads although some attention was also given to size of the sweat droplets. The silicone mold sweat test (SMS-T) is noninvasive, can be evaluated repeatedly in the same animal, and tests the integrity of the sweat gland or the sympathetic cholinergic pathway, or both. In the first part of the study, the SMS-T was characterized; the dose-response function to pilocarpine and its repeatability were estimated; the SR to focal nerve injury and the absence of denervation hypersensitivity were demonstrated. In the second part, we showed that hyperglycemia produces a deficit in the SR that does not develop in euglycemia. With correction of hyperglycemia, the SR returns to normal.

\section{Methods}

\section{Standard SMS-T}

Sprague-Dawley male rats were placed in a specially designed restraining cage and sedated with pentobarbital sodium $(11 \mathrm{mg} / \mathrm{kg}$ s.c.). Pilocarpine nitrate, a drug that has a dominant muscarinic action (6 $\mathrm{mg} / \mathrm{kg}, 2 \%$ solution, $\mathrm{pH} 5.5$ ), was injected subcutaneously into the back $(15,16)$. Silicone molds of both feet were prepared 20 and 40 min after pilocarpine injection by using a mixture of $0.6 \mathrm{ml}$ of silicone base with two drops of accelerator (Syringe Elasticon, Kerr, Romulus, MI) from a 22-gauge hypodermic needle. The impression of the sweat droplets in the hardened silicone molds of the pads of the rear feet was directly visualized and counted under a dissecting microscope with oblique light. The amount of sweating was expressed as the number of sweat droplets per group of pads. The size of the sweat impressions was not critically evaluated because of their spatial arrangement. Patterns were permanently recorded in drawings using a camera lucida.

\section{Characteristics of the SMS-T}

Dose-response curve. The SMS-T was performed on each of six rats, 32-34 wk old, by using randomly assigned dosages of $1,2,4$, or 8 $\mathrm{mg} / \mathrm{kg}$ of pilocarpine given at 3-d intervals.

1. Abbreviations used in this paper: GC, good (glycemic) control; HbA1C, glycosylated hemoglobin; PC, poor (glycemic) control; SMS-T, silicone mold sweat test; SR, sweat responses; SZT, streptozocin. 
Repeatability. The SMS-T was performed on 12 rats, 32-34 wk old, 13-26 times (22 \pm 4 , mean $\pm \mathrm{SD})$ over a period of $3 \mathrm{mo}$. To assess tolerance, the SMS-T was performed every $3 \mathrm{~d}$ for a month on each of 13 rats. In two animals the period was extended to $60 \mathrm{~d}$.

Effect of focal nerve injury and testing denervation hypersensitivity. Under pentobarbital anesthesia, either the right or left (by random assignment) sciatic nerve of 11 rats, 26-28 wk old, was exposed and mobilized for a short distance. A wooden stick, with a needle thermocouple attached to it, was positioned beneath the nerve and the nerve was frozen to $-48^{\circ} \mathrm{C}$ for 3 min with a nitrous oxide cryode (Frigitronics, NJ) at a point $8 \mathrm{~mm}$ below the sciatic notch. The saphenous nerve was cut at midthigh to prevent collateral sprouting. The SMS-T was performed three times before operation and every $6 \mathrm{~d}$ for the next $60 \mathrm{~d}$.

To determine whether denervation hypersensitivity occurred, two animals underwent bilateral sciatic and saphenous nerve transection with removal of $20 \mathrm{~mm}$ of the nerves. Proximal and distal stumps were inserted and sutured into muscles. The SMS-T was performed every 6 $\mathrm{d}$ for $60 \mathrm{~d}$.

Analysis of the sweat response. In characterizing the SMS-T response, 6 of 11 pads of the right or left rear foot (alpha, beta, B, 2, 3, 4 according to Kennedy's terminology (15)) were identified and the number of sweat droplets on each was counted. For each pad the time point with the highest number of sweat droplets was selected. The SR was expressed as the total number of sweat droplets for 6 of the 11 pads (number of droplets per six pads). Each silicone mold was coded to be evaluated blindly.

\section{Diabetes and the sweat response}

Experimental groups and study design. Rats, 32-34 wk old, housed singly in cages on wood shavings and exposed to light from 6 a.m. to 6 p.m., were randomly assigned to diabetic and control groups and followed for $30 \mathrm{wk}$. Diabetes was induced with one injection of streptozocin (Zanosar; Upjohn, Kalamazoo, MI) $(35 \mathrm{mg} / \mathrm{kg}$ i.p.) after an overnight fast (14 rats). After 2 wk of uncontrolled hyperglycemia (blood glucose $\geq 18.2 \mathrm{mmol} / \mathrm{liter}$ ), the diabetic animals were randomly assigned to the GC group (seven rats) and the PC group (seven rats). After 20 wk the GC and PC groups were reversed. The rats in the GC group became the GC $\rightarrow$ PC rats and the rats in the PC group became the $\mathrm{PC} \rightarrow \mathrm{GC}$ rats.

For the GC group the goal was to maintain the blood glucose level between 5 and $10 \mathrm{mmol} /$ liter. Ultralente insulin (Eli Lilly and Co., Indianapolis, IN) was injected subcutaneously three times a day (4 p.m., 12 p.m., and 8 a.m.). In one of the seven animals two injections were adequate. The diet was adjusted by weight (24-30 g of rat chow; Ralston-Purina, St. Louis, MO) and divided into portions to be given after each of the insulin injections; $85-100 \%$ of diet and insulin were given during the night hours. Insulin dosages and diet were individualized to maintain blood glucose level within the goal limits.

For the PC group the goal was to maintain the blood glucose level between 19 and $22 \mathrm{mmol} /$ liter. Ultralente insulin was injected subcutaneously zero to one times a day (4 p.m.). The diet was available ad lib.

Seven rats served as controls. During the first $2 \mathrm{wk}$ from the induction of diabetes (in the other two groups) their diet was restricted to approximate the weight loss experienced by the diabetic animals. Thereafter, the diet was adjusted to reach and maintain a weight of about $550 \mathrm{~g}$.

Blood glucose determination and monitoring. The blood glucose level was measured on a drop of whole blood from the tail by using the Glucostix and a Glucometer (Miles Laboratories Inc., Elkhart, IN). In the GC group the blood glucose level was assessed three times daily (4 p.m., 12 p.m., and 8 a.m.) for the first 10 days, then twice a week. In the PC group the blood glucose level was assessed three times a day once a week; in the control group, measurements were done once a month. Every $40 \mathrm{~d}$ from the induction of diabetes, the glycosylated hemoglobin (HbAlC) was measured in all the animals on $300 \mu$ l of whole blood from the tail. The HbAIC was assessed on hemolysates of erythrocytes separated into two chromatographic fractions by a boronate affinity column (17).

Evaluating the sweat response. The SMS-T was performed every 2 $\mathrm{d}$ for $2 \mathrm{wk}$ before the induction of diabetes, for $2 \mathrm{wk}$ of uncontrolled hyperglycemia, and in the first $2 \mathrm{wk}$ of insulin therapy. Then, SMS-T was performed once a week for $12 \mathrm{wk}$ and once every $2 \mathrm{wk}$ thereafter. After crossover, the rate of the SMS-T was increased (see Fig. 6).

Assessment of failure rates of individual sweat glands. The molds were coded for masked evaluation. A map of the position of each sweat droplet on the beta pad was drawn from the first evaluations. In molds from subsequent evaluations, the presence or absence of each sweat droplet could then be assessed by comparison to this original map. Only those impressions related to original sweat droplet position were counted. Spurious impressions were rare. The SR was expressed as the total number of sweat droplets in the beta pads of both rear feet (number of droplets per beta pads).

Statistical analysis. The means of the SR among the three groups of animals were compared by two-sample $t$ test. Because of the number of comparisons, the significance level was set at $P<0.01$. A randomizedblock analysis of variance was used to assess whether the failures were randomly distributed or clustered among the different sweat glands in the same animal (18). A runs test based on run lengths was used to verify this result (19).

\section{Results}

Characteristics of the SMS-T. The test was well tolerated and without known complications. Recovery from the procedure appeared to be complete in $60 \mathrm{~min}$. In addition to the $S R$, and beginning $3 \mathrm{~min}$ after pilocarpine injection, cholinergic overactivity was observed (salivation, widening of the palpebral fissure, and intestinal hypermotility).

The dose-response curve is shown in Fig. 1. With 1 or 2 $\mathrm{mg} / \mathrm{kg}$, activation of sweat glands was incomplete and sweat droplets were fewer and smaller than at higher doses. At 4 $\mathrm{mg} / \mathrm{kg}$, the SR number of droplets per six pads and the size of droplets was as large as at higher doses. For subsequent experiments a supramaximal dose of pilocarpine $(6 \mathrm{mg} / \mathrm{kg})$ was chosen.

The coefficient of variation of the number of droplets per six pads for 12 control rats averaged $7.7 \% \pm 1.8 \%$. We considered this to be an acceptably low degree of variability, permitting subsequent experiments.

Tolerance was not found when the SMS-T was performed every $3 \mathrm{~d}$.

Denervation of the foot pads resulted in disappearance of sweating in response to pilocarpine. At $6 \mathrm{~d}, 98 \%$ of the sweat droplets had disappeared; by $12 \mathrm{~d}, 100 \%$ had disappeared; and at $30 \mathrm{~d}$, no recovery was observed. The SR started to recover at $36 \mathrm{~d}$, and by $60 \mathrm{~d} 33 \%$ of the sweat droplets had reappeared. This pattern of recovery seemed to mirror the expected partial reinnervation of sweat glands. In the two rats in which regen-

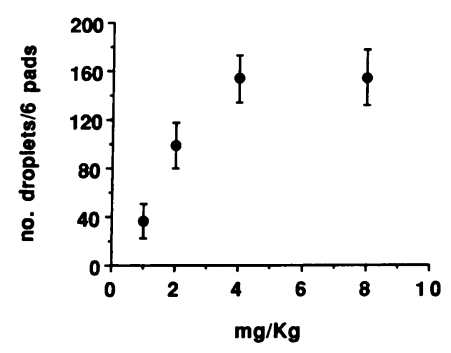

Figure 1. Dose-response curve for pilocarpine. SR (number of droplets per six pads, mean \pm SEM) in six rats to $1,2,4$, or $8 \mathrm{mg} / \mathrm{kg}$ of pilocarpine, given subcutaneously in random order every $3 \mathrm{~d}$. 


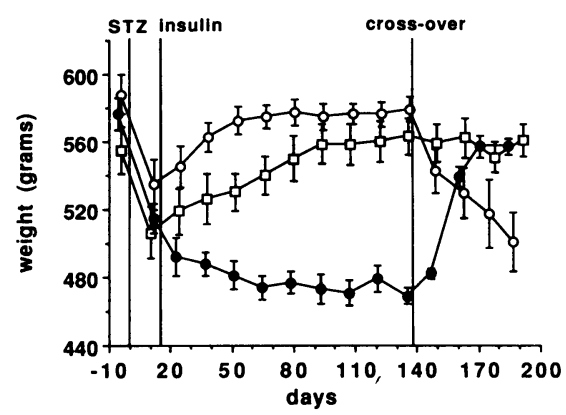

Figure 2. Weight (mean $\pm \mathrm{SEM}$ ) in the control group (open square) and in the two diabetic groups, GC (open circle) and PC (closed circle), before the induction of diabetes with streptozocin (STZ), after the assignment to GC and PC groups (insulin), and after the crossover of their glycemic control. There were seven rats in each group.

eration was prevented, the SMS-T did not evoke any SR for 60 $\mathrm{d}$, demonstrating that hypersensitivity to cholinergic agonists had not developed after denervation of the sweat glands.

Diabetes and the sweat response. The streptozocin-injected rats without treatment for $2 \mathrm{wk}$ lost weight and glycemia averaged $\sim 20 \mathrm{mmol} /$ liter (Figs. 2 and 3). Their food intake doubled (from 25 to $50 \mathrm{~g} / \mathrm{d}$ ) and their water intake quadrupled (from 50 to $200 \mathrm{ml} / \mathrm{d}$ ).

After random assignment to GC or PC groups, the GC rats received an average of $3.2 \mathrm{U}$ of insulin/day (Fig. 4). With careful control of diet and insulin therapy, an average blood glucose level of 7-9 mmol/liter was achieved (Fig. 3). Although monitored as often as four or more times per day on many occasions, no clinical manifestations of hypoglycemia were ever observed and a blood glucose level $<2.2 \mathrm{mmol} / \mathrm{liter}$ was only rarely detected ( $<1 \%$ of the time). The $\mathrm{HbAlC}$ was not significantly different from that of the control rats $(P$ $>0.10$ ) (Fig. 5). The PC rats received small doses of insulin to stabilize the metabolic abnormalities (Fig. 4). Their blood glucose was maintained at a level averaging $21 \mathrm{mmol} /$ liter with an average $\mathrm{HbA1C}$ of $14-15 \%$ (Figs. 3 and 5). The weight loss averaged $\sim 18 \%$ of baseline levels (Fig. 2). The metabolic indices for PC rats were significantly different from those of the control rats and GC rats $(P<0.001)$.

At $20 \mathrm{wk}$ after crossover, the GC $\rightarrow$ PC rats showed a

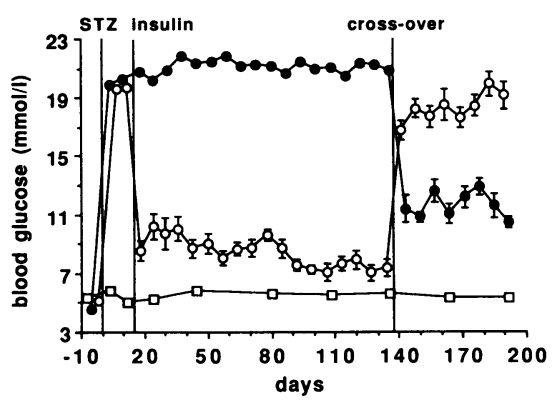

Figure 3. Blood glucose (mean \pm SEM) in the control group (open square) and in the two diabetic groups, GC (open circle) and PC (closed circle), before the induction of diabetes with STZ, after the assignment to GC and PC groups (insulin), and after the crossover of their glycemic control. There were seven rats in each group. (In the PC group the values are expressed as mean of medians because values $>22.2 \mathrm{mmol} /$ liter are given as "Hi" by the glucometer.)

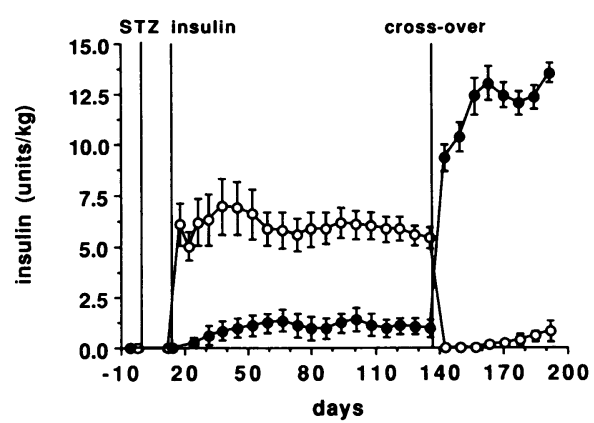

Figure 4. Insulin requirement (mean \pm SEM) in the two diabetic groups, GC (open circle) and PC (closed circle), since the induction of diabetes with STZ, after the assignment to GC and PC groups (insulin), and after the crossover of their glycemic control. There were seven rats in each group.

worsening of metabolic control but the weight loss was less dramatic, the blood glucose level less severe (averaging $\sim 19$ $\mathrm{mmol} /$ liter), and the $\mathrm{HbAlC}$ lower (averaging 12\%) (Figs. 2,3 , and 5) than it had been in the PC group. The insulin demand was also lower: five rats did not need insulin.

It was more difficult to achieve euglycemia in the PC $\rightarrow$ GC group. This group of animals showed wide fluctuations of blood glucose level akin to what has been described as "brittle diabetes" in man. The insulin demand was about twice that of the GC group, even after stabilization of weight and use of comparable diets (Fig. 4). One episode of clinical hypoglycemia was observed and $\sim 2 \%$ of the blood glucose determinations were $<2.2 \mathrm{mmol} /$ liter. The blood glucose level in the PC $\rightarrow$ GC group averaged $\sim 11 \mathrm{mmol} /$ liter but the $\mathrm{HbAlC}$ remained within normal limits (Figs. 3 and 5), suggesting a mean glycemia nearer to the normal values than that assessed $8 \mathrm{~h}$ after the insulin injections.

The average SR in the three groups (control, GC, and PC groups) are shown in Fig. 6. During the baseline period the number of sweat glands activated by pilocarpine gradually increased, reaching a maximum after four tests (from 28.5 \pm 9.8 to $32.0 \pm 10.2$, mean $\pm \mathrm{SD}, P<0.001$ ).

Not all sweat droplets sites were activated at each test, even in control rats. The percent of all sites activated in this group was $\sim 90 \%$.

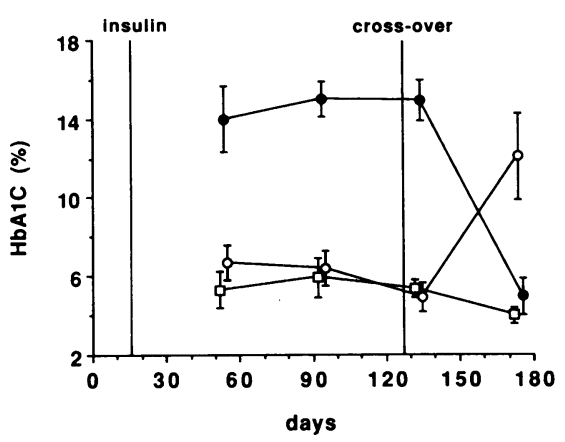

Figure 5. HbAlC (mean $\pm \mathrm{SEM})$ in the control group (open square) and in the two diabetic groups, GC (open circle) and PC (closed circle), from the induction of diabetes with STZ, before and after the crossover of their glycemic control. There were seven rats in each group. 


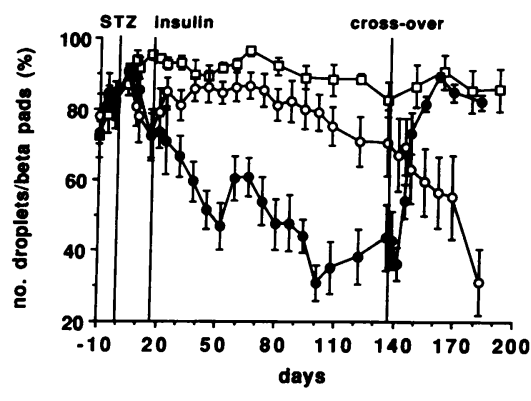

Figure 6. SR (number of droplets per beta pads, mean \pm SEM) in the control group (open square) and in the two diabetic groups,.GC (open circle) and PC (closed circle) before the induction of diabetes with STZ, after the assignment to GC and

PC groups (insulin), and after the crossover of their glycemic control. There were seven rats in each group.

During the first 2 wk of hyperglycemia, the SR remained unchanged despite severe metabolic abnormalities. In the PC rats, the SR started to decline and reached significance only after $16 \mathrm{~d}(P<0.005$ compared with control rats). Thereafter, the SR in the PC group gradually worsened and reached a level of only $40 \%$ of the maximal response $(P<0.001)$. After crossover, the SR of the PC $\rightarrow$ GC group began to improve at $9 \mathrm{~d}$ and was not significantly different from controls by $12 \mathrm{~d}$.

The SR in the GC group did not differ significantly from that of the control rats during the first 20 wk of the study. After crossover the SR in the GC $\rightarrow$ PC group declined and was significantly different from that of the control rats at $26 \mathrm{~d}(P$ $<0.01$ )

Because the pattern of sweat glands unresponsive to pilocarpine might provide clues as to pathogenetic mechanisms, the distribution of failures among the sweat glands was analyzed for 19 successive time points (from day 16 to day 136) in the three groups (control, GC, and PC). The number of absences of sweat responses for each sweat gland is shown in Fig. 7. The failure to respond to pilocarpine appeared to be unevenly distributed among the sweat glands in all three groups of rats (control rats: $F=5.4 \pm 1.9, P<0.002$; GC rats: $F$ $=8.9 \pm 2.6$; and $P C$ rats: $F=12.3 \pm 1.7, P<0.001)$. The analysis of the run lengths of the absence of sweat droplets was assessed in rats in poor control because of the high rate of failures (Table I). The results suggested clustering and not a random or a systematic distribution $\left(\chi^{2}=209 \pm 34, d f\right.$ $=107 \pm 19, P<0.001)$.

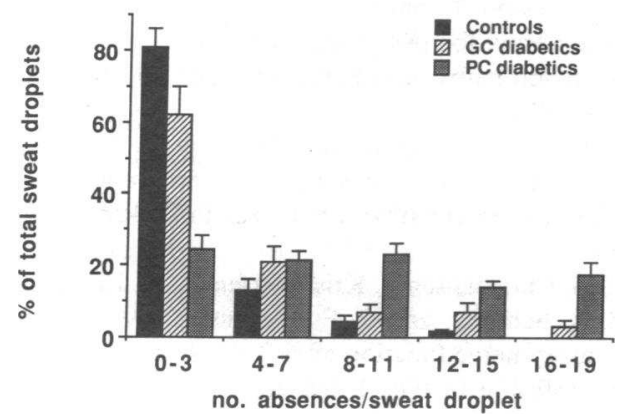

Figure 7. Frequency distribution of the number of absences for each sweat droplet (mean \pm SEM) in the control group, in the GC diabetics, and in PC diabetics from day 16 to day 136 since the induction of diabetes, for 19 time points. There were seven rats in each group.
Table I. Observed Run Lengths (Mean \pm SD) of the Presence and Absence of the Single Sweat Droplets

\begin{tabular}{ccr} 
Run & \multicolumn{2}{c}{ Frequency } \\
\cline { 2 - 3 } length & Presence & Absence \\
\hline 1 & $41.4 \pm 5.7$ & $52.3 \pm 9.0$ \\
$2-3$ & $33.9 \pm 14.5$ & $24.4 \pm 8.5$ \\
$4-5$ & $9.1 \pm 3.3$ & $7.0 \pm 2.2$ \\
$6-7$ & $7.9 \pm 2.9$ & $5.6 \pm 3.4$ \\
$8-9$ & $3.7 \pm 2.8$ & $3.1 \pm 1.5$ \\
$10-11$ & $2.3 \pm 1.1$ & $1.0 \pm 1.0$ \\
$12-13$ & $2.0 \pm 2.0$ & $1.7 \pm 1.7$ \\
$14-15$ & $2.0 \pm 1.9$ & $1.6 \pm 1.5$ \\
$16-17$ & $1.4 \pm 1.3$ & $1.4 \pm 1.9$ \\
$18-19$ & $1.9 \pm 1.9$ & $1.6 \pm 1.1$ \\
& &
\end{tabular}

In the seven diabetic animals in PC, from day 16 to day 136 since the induction of diabetes, for 19 time points. Number of presence runs $=105.6 \pm 23.9$; number of absence runs $=99.9 \pm 14.6$.

\section{Discussion}

In human diabetic polyneuropathy, dysfunction and degeneration of motor, sensory, or autonomic fibers of peripheral nerves are characteristic (20). In experimental diabetes, on the other hand, although some of the functional abnormalities of diabetic neuropathy may have been mimicked $(7,11)$, only a few neuropathic deficits have been reported (21) and these are generally of small magnitude. Fiber degeneration or loss has generally not been demonstrated. In addition, it is unclear whether in experimental diabetes the deficits are of the same kind and are induced by the same mechanisms as in human neuropathy.

Abnormalities of nerve conduction in human diabetic neuropathy may be explained by loss of fibers, demyelination and remyelination, and possibly physiologic events at nodes of Ranvier $(22,23)$. Neuropathy usually develops in diabetics whose hyperglycemia has been treated for several or many years. In experimental diabetes the decreased nerve conduction velocity develops in metabolically uncontrolled diabetes and is generally not thought to be due to loss of fibers or to demyelination and remyelination. The decreased nerve conduction may be due to fiber shrinkage (24), cellular axonal atrophy (11), altered nodal events (25), or combination of these or other events. Muscle weakness and electromyographic alterations and sensory loss typical of human diabetic neuropathy have not been characteristic of experimental diabetes. By contrast, some of the autonomic disturbances encountered in human diabetic neuropathy have also been found in experimental diabetes. The present experimental model is of interest because one manifestation of human diabetic neuropathy, decreased sweating, develops and can be quantitated. It is now possible to study the metabolic and cellular events which might relate to the development of this manifestation of diabetic neuropathy so as to understand its mechanism and to test whether therapy can be used to prevent or ameliorate it.

There are several approaches to characterize and quantitate sweating function (26). They rely on: (a) the cutaneous distribution of anhydrosis when the body temperature is ele- 
vated; $(b)$ the volume of sweat produced in a given area of the skin when a chemical is injected or iontophoresed into the skin; and (c) the number of sweat droplets per skin area or the size of the droplets. In this study we used the number of sweat droplets per hind foot pads of rats as a measure of the SR to a standard dose of pilocarpine.

The analysis of the number and size of sweat droplets on silicone molds of the skin has been used in man to assess sudomotor activity $(27,28)$. This simple test appears to be accurate in reproducing the surface anatomic features of sweat glands and to provide an end point of sudomotor abnormality that may reflect diabetic sweat gland dysfunction or denervation (29). The advantages of the SMS-T are that it can be performed in an affected region, is not invasive or destructive, can be used in man or in animals, can be repeated, and provides quantitative data.

The reason for the initial increase in the average number of sweat droplets is unclear. Acclimatization seems unlikely since the animals were housed in the same conditions for several months before onset of the trials. Other possibilities include a training effect (30) or unplugging of sweat pores (31).

We have shown that the SR disappears with denervation and that denervation hypersensitivity is not a confounding problem. This supports previous observations showing that sweat gland of the rat $(32)$, mouse $(15,16)$, and man $(33,34)$ that have been denervated become unresponsive to cholinergic agonists. When the denervated sweat glands in the rat and in the mouse are reinnervated they recover the response to cholinergic agonists. The sympathetic cholinergic innervation and the presence of acetylcholine appear to be required for the induction and the maintenance of sweat production in the rat (35). The basis of the unresponsiveness of the denervated sweat glands to direct stimulation with cholinergic agonists is not understood, but the defect might be consequent to a decreased number of muscarinic receptors (36) or related to postreceptor events in sweat production.

The maintenance of different levels of blood glucose control (as done here) allows evaluation of the role of hyperglycemia in the pathogenesis of diabetic complications and of the efficacy of insulin treatment in their prevention and amelioration. The end point of neuropathy that has been studied most extensively in animal models is nerve conduction, axonal transport, and neuropathologic and morphometric features of nerves $(8,9)$. Many of the neuropathic abnormalities that develop in association with severe hyperglycemia have been shown to be prevented by insulin treatment (7-14). In general, the degree of blood glucose control has dramatically influenced outcome $(13,14)$. One injection of insulin a day, even with the long-acting heat-treated variety, has been less successful in preventing the neuropathic manifestations (37), and its use has been associated with a low rate of axonal degeneration (12), possibly related to hypoglycemia.

Attempts to normalize blood glucose level in diabetic rats appear to present the investigator with the same problems encountered by the diabetologist trying to achieve the same end in diabetic patients. This study has demonstrated that good glycemic control could be obtained by adjusting calories in an attempt to reach given rat weights, splitting the diet into defined aliquots given at predetermined times, and using multiple daily injections of Ultralente insulin. The risk of severe and prolonged hypoglycemia was substantially decreased, we thought, by this approach. The early achievement of good control of blood glucose may have exerted a favorable effect on the diabetic condition (38).

Using the SMS-T, we have demonstrated that the SR is diminished by hyperglycemia. This model, an extension of earlier studies performed by Kennedy $(15,16,29)$ and by Landis $(35,39)$, may be a useful one in dissecting out the metabolic events involved and the therapeutic agents that would ameliorate the abnormality. In the present study we have, in fact, shown unequivocally that good glycemic control can prevent or ameliorate the sweating abnormality. It appears that one neuropathic deficit characteristic of human diabetic neuropathy (26) can be prevented and ameliorated in the animal model.

The mechanisms by which hyperglycemia inhibits sweating can now be studied given that a model is available. The present data cannot be used to understand underlying mechanisms but some inferences may be justified. Four observations must be taken into account. First, there is a lag between the development of hyperglycemia and the development of the sweating abnormality. Second, the effect appears to be cumulative, the deficit worsening between 16 and $100 \mathrm{~d}$. Third, there is rapid reversibility. Fourth, there is clustered sweat gland failure. These changes might best be explained by metabolic or structural derangements in the sweat glands themselves, in the terminal axons of sudomotor fibers, or could be preneuronal or preglandular (vascular, hormonal, related to growth factors, interfering metabolites, or other).

\section{Acknowledgments}

This investigation was supported in part by a Peripheral Neuropathy Center grant from the National Institute of Neurologic and Communicative Diseases and Stroke (NS 14304), a center grant from the Muscular Dystrophy Association and the Mayo, Borchard, Upton, and Whirlpool Funds.

\section{References}

1. Melton, L. J. III, and P. J. Dyck. 1987. Epidemiology. In Diabetic Neuropathy. P. J. Dyck, P. K. Thomas, A. K. Asbury, A. I. Winegrad, and D. Porte Jr., editors. W. B. Saunders Co., Philadelphia. 27-35.

2. Service, F. J., R. A. Rizza, J. R. Daube, P. C. O'Brien, and P. J. Dyck. 1985. Near normoglycemia improved nerve conduction and vibration sensation in diabetic neuropathy. Diabetologia. 28:722-727.

3. Dahl-Jørgensen, K., O. Brinchmann-Hansen, K. F. Hanssen, T. Ganes, P. Kierulf, E. Smeland, L. Sandvik, and Ø. Aagenaes. 1986. Effect of near normoglycemia for two years on progression of early diabetic retinopathy, nephropathy, and neuropathy: the Oslo study. Br. Med. J. 293:1195-1199.

4. Solders, G., H. Wilczec, R. Gunnarsson, G. Tydén, A. Persson, and C.-G. Groth. 1987. Effects of combined pancreatic and renal transplantation on diabetic neuropathy: a two-year follow-up study. Lancet. ii:1232-1235.

5. Jakobsen, J., J. S. Christiansen, I. Kristoffersen, C. K. Christensen, K. Hermansen, A. Schmitz, and C. E. Mogensen. 1988. Autonomic and somatosensory nerve function after 2 years of continuous subcutaneous insulin infusion in type I diabetes. Diabetes. 37:452455.

6. Adam van der Vliet, J., X. Navarro, W. R. Kennedy, F. C. Goetz, J. S. Najarian, and D. E. R. Sutherland. 1988. The effect of pancreatic transplantation on diabetic polyneuropathy. Transplantation (Baltimore). 45:368-370.

7. Greene, D. A., P. V. DeJesus, and A. I. Winegrad. 1975. Effects 
of insulin and dietary myo-inositol on impaired peripheral motor nerve conduction velocity in acute streptozocin diabetes. J. Clin. Invest. 55:1326-1336.

8. Sharma, A. K., and P. K. Thomas. 1987. Animal models: pathology and pathophysiology. In Diabetic Neuropathy. P. J. Dyck, P. K. Thomas, A. K. Asbury, A. I. Winegrad, and D. Porte Jr., editors. W. B. Saunders Co., Philadelphia. 237-252.

9. Sidenius, P., and J. Jakobsen. 1987. Axonal transport in human and experimental diabetes. In Diabetic Neuropathy. P. J. Dyck, P. K. Thomas, A. K. Asbury, A. I. Winegrad, and D. Porte Jr., editors. W. B. Saunders Co., Philadelphia. 260-265.

10. Low, P. A. 1987. Recent advances in the pathogenesis of diabetic neuropathy. Muscle \& Nerve. 10:121-128.

11. Jakobsen, J. 1979. Early and preventable changes of peripheral nerve structure and function in insulin-deficient diabetic rats. $J$. Neurol. Neurosurg. Psychiatry. 42:509-518.

12. Sharma, A. K., I. G. M. Duguid, D. S. Blanchard, and P. K. Thomas. 1985. The effect of insulin treatment on myelinated nerve fibre maturation and integrity and on body growth in streptozocin-diabetic rats. J. Neurol. Sci. 67:285-297.

13. McCallum, K. N. C., A. K. Sharma, D. S. Blanchard, D. Stribling, D. J. Mirrless, I. G. M. Duguid, and P. K. Thomas. 1986. The effect of continuous subcutaneous insulin infusion therapy on morphological and biochemical abnormalities of peripheral nerves in experimental diabetes. J. Neurol. Sci. 74:55-67.

14. Sima, A. A. F., W. Zhang, W. J. Tze, J. Tai, and V. Nathaniel. 1988. Diabetic neuropathy in STZ-induced diabetic rat and effect of allogeneic islet cell transplantation: morphometric analysis. Diabetes. 37:1129-1136.

15. Kennedy, W. R., M. Sakuta, and D. C. Quick. 1984. Rodent eccrine sweat glands: a case of multiple efferent innervation. Neuroscience. 11:741-749.

16. Kennedy, W. R., and M. Sakuta. 1984. Collateral reinnervation of sweat glands. Ann. Neurol. 15:73-78.

17. Yue, D. K., S. McLennan, D. B. Church, and J. R. Turtle. 1982. The measurement of glycosylated hemoglobin in man and animals by aminophenyl-boronic acid affinity chromatography. Diabetes. 31:701-705.

18. Kleinbaum, D. G., L. L. Kupper, and K. E. Muller. 1988. Applied regression analysis and other multivariable methods. PWSKent Publishing Co., Boston. 297-313.

19. O'Brien, P. C., and P. J. Dyck. 1985. A run test based on run lengths. Biometrics. 41:237-244.

20. Thomas, P. K., and S. G. Eliasson. 1984. Diabetic neuropathy. In Peripheral Neuropathy. P. J. Dyck, P. K. Thomas, E. H. Lambert, and R. Bunge, editors. W. B. Saunders Co., Philadelphia. 1773-1810.

21. Sima, A. A. F., T. Brismar, and S. Yagihashi. Neuropathies encountered in the spontaneously diabetic BB Wistar rat. In Diabetic Neuropathy. P. J. Dyck, P. K. Thomas, A. K. Asbury, A. I. Winegrad, and D. Porte Jr., editors. W. B. Saunders Co., Philadelphia. 253-259.

22. Dyck, P. J., W. R. Sherman, L. M. Hallcher, F. J. Service, P. C. O'Brien, L. A. Grina, P. J. Palumbo, and C. J. Swanson. 1980. Human diabetic endoneurial sorbitol, fructose, and myo-inositol related to sural nerve morphometry. Ann. Neurol. 8:590-596.
23. Dyck, P. J., A. C. Lais, J. L. Karnes, P. C. O'Brien, and R. Rizza. 1986. Fiber loss is primary and multifocal in sural nerves. Ann. Neurol. 19:425-439.

24. Dyck, P. J., E. H. Lambert, A. J. Windebank, A. C. Lais, M. F. Sparks, J. L. Karnes, W. R. Sherman, L. M. Hallcher, P. A. Low, and F. J. Service. 1981. Acute hyperosmolar hyperglycemia causes axonal shrinkage and reduced nerve conduction velocity. Exp. Neurol. 71:507-514.

25. Sima, A. A. F., S. A. Lattimer, S. Hagihashi, and D. A. Greene. 1986. Axoglial dysjunction. A novel structural lesion that accounts for poorly-reversible nerve conduction slowing in the spontaneously-diabetic Bio-breeding rat. J. Clin. Invest. 77:474-485.

26. Low, P. A., and R. D. Fealey. 1987. Sudomotor neuropathy. In Diabetic Neuropathy. P. J. Dyck, P. K. Thomas, A. K. Asbury, A. I. Winegrad, and D. Porte Jr., editors. W. B. Saunders Co., Philadelphia. 140-145.

27. Sarkany, I., and P. Gaylarde. 1968. A method for demonstration of sweat gland activity. Br. J. Dermatol. 80:601-605.

28. Harris, D. R., B. F. Polk, and I. Willis. 1972. Evaluating sweat gland activity with imprint techniques. J. Invest. Dermatol. 58:78-84.

29. Kennedy, W. R., M. Sakuta, D. Sutherland, and F. C. Goetz. 1984. Quantitation of the sweating deficiency in diabetes mellitus. Ann. Neurol. 15:482-488.

30. Banjar, W. M. A., C. M. Bradshaw, and E. Szabadi. 1989. Seasonal variation in responsiveness of human eccrine sweat glands to phenylephrine. Br. J. Clin. Pharmacol. 27:276-278.

31. Sato, K., H. Kang, and K. T. Sato. 1989. Biology of sweat glands and their disorders. I. Normal sweat gland function. J. Am. Acad. Dermatol. 20:537-563.

32. Hayashi, H., and T. Nakagawa. 1963. Functional activity of the sweat glands of the albino rat. J. Invest. Dermatol. 41:365-367.

33. Janowitz, H. D., and M. I. Grossman. 1950. The response of the sweat glands to some locally acting agents in human subjects. J. Invest. Dermatol. 14:453-458.

34. Silver, A., A. Versaci, and W. Montagna. 1963. Studies of sweating and sensory function in cases of peripheral nerve injuries of the hand. J. Invest. Dermatol. 40:243-258.

35. Stevens, L. M., and S. C. Landis. 1987. Development and properties of the secretory response in rat sweat glands: relationship to the induction of cholinergic function in sweat gland innervation. Dev . Biol. 123:179-190.

36. Grant, M. P., and S. C. Landis. 1988. Expression of muscarinic cholinergic receptors on rat sweat glands. Neuroscience. 14(part 1):427a. (Abstr.)

37. Larsen, J. R., and P. Sidenius. 1989. Slow axonal transport of structural polypeptides in rat, early changes in streptozocin diabetes, and effect of insulin treatment. J. Neurochem. 52:390-401.

38. Shah, S. C., J. I. Malone, and N. E. Simpson. 1989. A randomized trial of intensive insulin therapy in newly diagnosed insulin-dependent diabetes mellitus. $N$. Engl. J. Med. 320:550-554.

39. Landis, S. C., R. E. Siegel, and M. Schwab. 1988. Evidence for neurotransmitter plasticity in vivo. II. Immunocytochemical studies of rat sweat gland innervation during development. Dev. Biol. 126:129140. 